\title{
Reflections on Nursing Educational Advancement Within Diverse and Evolving National Cultural Contexts
}

\author{
${ }^{1}$ School of Social Science \& Health, Pontificial Universidade Catolica de Gioas, Goiania, Goias, Brazil \\ ${ }^{2}$ School of Nursing, Fujian Medical University, Fuzhou, Fujian, China \\ ${ }^{3}$ School of Nursing, University of British Columbia, Vancouver, Canada \\ ${ }^{4}$ University of British Columbia, Vancouver, Canada, E-mail: sally.thorne@nursing.ubc.ca
}

\begin{abstract}
:
As the development of nursing education becomes increasingly internationalized, it is tempting to focus on universal aspects of the discipline rather than explicitly emphasizing the distinct national cultures and contexts within which our profession and its educational styles and approaches have evolved. Capitalizing on an opportunity for comparative critical reflection on the relevant political, economic and social histories that have underpinned the development of nursing education in China, Brazil and Canada - three countries united by shared values about equity and access to health services - we sought to deconstruct the manner in which these forces have shaped the national differences in the way we conceptualize and deliver nursing education. On this basis, we examined the implications for the advancement of nursing education within each national context, recognizing the fundamental relevance of indepth critical reflection for optimizing nursing's advocacy capacity within each of our national health care and policy systems.
\end{abstract}

Keywords: advocacy, health policy, national culture, social context

DOI: 10.1515/ijnes-2018-0017

Received: April 5, 2018; Accepted: April 5, 2018

Nursing education occurs within the context of a national character or culture, which itself is shaped by the political, economic and social history of each of our countries. Although organized nursing occurs in all modern societies, and we consider its common core values and principles of to be shared in some form across all jurisdictions (Egenes, 2018), our health care structures and the educational systems we create to provide our nations with the professional workforce for the next generation remain multifaceted and varied (Mossialos, Djordjevic, Osborn, \& Sarnak, 2017). Both the practice of nursing and the preparation of new nurses are situated at a particular point within national history and tradition, inevitably reflecting its variations and diversities.

As our world internationalizes, and we become an increasingly mobile workforce, nurses are called upon to consider who they are within the wider spectrum of the profession globally. Informed critical reflection can facilitate an understanding of the manner in which their positionality within their own national cultural context will have shaped elements of their practice and thinking with respect to what the profession constitutes and how it enacts its mandate on behalf of society. Toward this end, we capitalized on an opportunity for extended dialogue between nurse educators from three quite distinct national cultures to examine some of the relevant political, economic and social histories that have underpinned the development of nursing education in our various contexts, deconstructing how these forces seem to have shaped the way we deliver our nursing education and uncovering insights about what that might mean for each of our nations as nursing education advances. On the basis of this exercise, we found that a critically reflective approach can help nurse educators better understand their own national culture, such that they can unpack the manner in which it shapes their work in preparing the next generation of practitioners. When we come to appreciate the assumptions and shared blindspots that we may hold by virtue of each of our national cultures, we can begin to appreciate our distinctive professional lenses on global nursing issues. By embracing a critically reflective curiosity about what our own national positioning affords in terms of our capacity to think broadly about this profession and its educational enterprise, we hope to expand access to the possibilities that our situatedness might have obscured and inspire our colleagues to engage in dialogue with "the other" in the nursing education universe.

Sally Thorne is the corresponding author.

(c) BY-NC-ND () 2018 published by De Gruyter.

This work is licensed under the Creative Commons Attribution-NonCommercial-NoDerivatives 4.0 License. 


\section{Background}

By virtue of overlapping visiting scholar international engagement opportunities, permitting JZ from China and VV from Brazil to work with ST and ET at the University of British Columbia in Canada, we had the good fortune of extended focused dialogue into matters of nursing educational development. Over the course of many months, our conversation progressed from a shared expectation that learning about nursing educational development would be primarily unidirectional (developed to developing nations) to a more multilateral intrigue about how powerfully our current nursing educational challenges and therefore possibilities for future development were shaped by the distinctive historical, social, economic and political climate of our nations. It also progressed from assumptions oriented around general similarities between our three health care systems (primarily as regards the value of a publicly funded health care system) to a more nuanced understanding of how these distinctive political and social histories, events and conditions have found their way into nursing education as it exists today, and therefore the challenges it will face tomorrow.

As the dialogue progressed, our capacity to deepen interrogation of one another's ideas and assumptions about nursing, health care, and society expanded. We questioned how and why certain ideas and practices had become established and accepted in our various nursing educational systems, and began to look beyond the nursing education literature and into the broader literature of our societal contexts in order to answer the questions that were surfacing. While learning about "the other" was informative, we also discovered that some of the best learning came from that which was reflected back to us about the national cultural contexts within which each of our own nursing educational systems have evolved. We began to realise that, like the fish unaware of the existence of water, there is much in the wider context of nursing education that that we take for granted and tend not to critically consider. This exercise therefore yielded numerous insights that were potentially useful not only to leadership in nursing educational development but also to our students and future graduates as they enter an increasingly internationalized world and will need insight as to what they bring to it.

To engage a wider community of dialogue about the subtle and nuanced manner in which each of us takes up aspects of the national cultures in which we reside, stamping those aspects upon the next generation of nursing in our countries, we describe some of what we came to appreciate as relevant national cultural contexts that have arguably influenced what nursing is, how it understands its role in the world, and therefore the educational challenges it now faces. For each country we highlight key social and political forces that seem to have played a role in creating the country's current character/national culture. From that standpoint, we then consider how those forces have influenced some of what our profession might consider prominent and influential characteristics of our health care systems the way they exist today. This kind of analysis helps us to discern the shape of nursing that may be needed to deal with those social and historical forces in the manner that expresses our profession's core and unifying values (Lu et al., 2018). Finally, we reflect on what can be learned from this kind of exercise as a path toward the kinds of insights that may truly unleash the international potential of our profession, in each of its manifestations, going forward.

\section{The people's republic of china: repression and rebirth}

Chinese nursing and nursing education have been undeniably shaped by that nation's politically turbulent past and its distinctive and rich social and cultural context. Much has been written about the remarkable history of nursing in the People's Republic of China, and although it is not our purpose to convey an indepth synthesis of that history, highlighting a few key aspects of it will clearly illustrate the powerful force of national cultural context on what we see in Chinese nursing education today.

Florence Nightingale's system of nursing was first introduced into China by Elizabeth McKechnie, a nurse of Scottish heritage who arrived in Shanghai in 1884 with the Women's Union Missionary Society of America to take part in the development of hospital nursing (Chan \& Wong, 1999). She was among the first wave of Western missionary nurses who became a pivotal influence on the ideas affecting China and its delivery of health care following the loss of the opium wars $(\mathrm{Xu}, \mathrm{Xu}, \&$ Zhang, 2000). The first school to train Chinese nurses was established by missionary nurses in Fuzhou City, Fujian in 1888 (Gao, Chan, \& Cheng, 2012; Watt, 2004). Nina Gage, an American nurse associated with the Yale Mission arrived in 1908 to establish a nursetraining program in Changsha, and when the Nurses Association of China (forerunner of the Chinese Nursing Association) elected its first officers in 1914, Miss Gage became its president (Chen, 1999). The Association joined the International Council of Nursing in 1922 (Li, 2014), and retained that membership until 1949 when the Communists came into power in China.

In 1920, Peking Union Medical College, founded by the Rockefeller Foundation for the purpose of bringing the best of modern scientific medicine to China, initiated the first collegiate nursing program with a five 
year curriculum specifically designed to produce excellent nurse educators (Chen, 1999). This was a significant event in that it launched Chinese nursing education at a tertiary level early in the development of the profession. Through the 1920s, Chinese women began to take on more leading roles in Chinese nursing and, in 1928, Wu Zheying (LilianWu, 伍哲英), the first principal of the Shanghai nursing school, became the first Chinese president of the Nurses Association of China (Yuhong, 2017). By 1930, the first secondary-level nursing school was launched that was funded by the national government rather than by foreign missions. Most programs were 3 or 4 years in length and delivered in hospitals. Over the following decades, the numbers of Chinese secondarylevel nursing schools steadily increased. Throughout all of this period, it is important to note that China was being rocked by episodes of war, including the 1911 Revolution; the Revolutionary Civil War (1924-1937); the Anti-Japanese War (1937-1945); and the War of Liberation (1946-1949) (Yan, An Li, \& McDonald, 2014). Thus the combined influence of both war and international intervention contributed significantly to the beginnings of Chinese professional nursing, its nursing education, and the early conception that Chinese nurses gained with respect to Western and international ideals.

The Communist Party came into power in China in 1949. Recognizing the extensive health needs of the population, the national government mandated the creation of numerous secondary nursing schools for the preparation nurses. In 1951, the first national education conference mandated by the new ruling party was held. At that meeting, a far-reaching decision was made to engage in nation-wide restructuring of the higher educational system, ranking those disciplines best suited to being situated in universities. Ranked as a secondary academic discipline through this process, nursing education was moved out of the universities. By 1952, Chinese baccalaureate nursing education had ceased to exist, not to be reinstated until 1983 (Gao et al., 2012).

In 1961, the Peking Second Medical College established a department of nursing to support working nurses engaged in further study, and in 1963, nursing was listed among the ten health-related specialties in higher education institutions (Xu et al., 2000). However, these efforts did not materialize in significant advancements due to the onset of the Cultural Revolution. In this context, from 1967 to 1977, education itself was deemed as non-essential and most school teachers were dismissed and sent to distant rural for "restructuring." Nursing schools were closed, and it became possible for anyone to act as a nurse, regardless of lack of experience or professional training. This widespread erosion of the public perception of nursing and the disruption of the nursing education system led to a significant deterioration of the quantity of nurses and the quality of nursing care. In response to this, from 1970 to 1977, short term nursing staff training programs were organized in some hospitals to provide the minimum basic skills to meet the health needs, but with ill prepared trainers, poor equipment and few resources. Over this period, clearly politics played a decisive role in the development of Chinese nursing education. Remnants of the widespread devaluing of nursing and deskilling of nursing education remain apparent in the social fabric today, with relatively few students selecting nursing as their first choice career option.

In 1978, China took up The Reform and Opening-up Policy which contributed to not only economic development but also every aspect of Chinese society. With a huge amount of information now being streamed into China, the Chinese government realized that the rapid development of higher education in advanced countries had placed them at considerable economic advantage, and consequently, a new national education system was established in response to secular stagnation. By 1983, a bachelor of nursing program was launched in Tianjin Medical University (Gao et al., 2012). In 1984, the National Ministry of Education and the National Ministry of Health held a nursing education forum to discuss the nursing education system and to set curriculum. Eventually, academic nursing was resumed after being abolished for over 30 years, opening up a new chapter for both nursing education and the nursing profession. By 1985, seven universities had initiated baccalaureate degree nursing education to prepare for higher level nursing professional practice and an expanded capacity for the quality of nursing care. Students were recruited from among high school graduates who had passed the highly competitive National University Admission Examinations. Naturally, in rapidly advancing to try to fill the gap of over a generation, there were a thousand aspects requiring the profession's attention. Thus, although this period marked the blooming stage of the recovery of tertiary level nursing education, Chinese bachelor's programs were insufficient to meet the enormous workforce demand, and two other levels of nursing program were also required: nursing programs delivered within health-oriented secondary schools, and collegiate nursing programs in colleges. Under the socioeconomic conditions of the early 1990s, and the national regulatory system that began in 1993, the biomedical model remained the dominant perspective, such that health was primarily understood as disease-based care, primarily understood as comprised of simple skillsets, learned through repetitive practice. Thus the lower levels of nursing education became the majority provider in this period, such that most nurses were trained in a manner that limited them to working in hospitals, providing basic care functions. In this context, graduate education emerged much later. In 1990, China's first Master of Science program began at Peking Union Medical University, and 2003 saw the introduction of the country's first doctoral level programs (Gao, Chan, \& Cheng, 202). 
Many elements deriving from China's unique historical trajectory remain in evidence in both professional practice and nursing education today (Yuhong, 2017). It remains a profession primarily for women, and much work has been put into rebuilding the idea of nursing as a noble and respectable profession for women established in the first half of the twentieth century. As China transforms itself into a global economic superpower, the world will be looking to it for nurses to fill impending shortages globally (Wang, Whitehead, \& Bayes, 2016). However, the public devaluing of nursing knowledge and skills persists, and the profession struggles to attract the top qualified candidates. Because of the one child policy, a "temporary" public policy initiative that ultimately lasted from 1979 until 2015 and has had an unquestionable impact on every facet of Chinese society (Hesketh \& Xing, 2005), generations of nursing students are all "only children," many of whom were brought up in an overprotective environment and may not be well suited to the maturity and competence required to meet the emotional needs of patients or to assume professional leadership roles (Chan \& Wong, 1999; Xu et al., 2000). Even in the university settings, the remnants of a workforce control ethos are in operation, such that faculty are expected to remain in their classrooms or offices for long hours, and have been quite limited in their capacity to carve out time for research. Graduate education is viewed primarily as a mechanism to train educators, and advanced practice has been somewhat slow to develop. These challenges aside, it is a testament to the tireless effort, vision and commitment of a cadre of strong and forceful nursing leaders that the profession has been able to build from the ashes of a lost profession the proud international presence Chinese nursing is beginning to realise today.

\section{Brazil: complexity and confidence}

Nursing education in Brazil also developed in the twentieth century, in the context of all of the social, political and economic complexities experienced by that society over the period, including numerous challenges within Brazilian education and health systems. Global movements such as industrialization, urbanization, migration and systemic changes in the economy (increases, decreases, crises, and advances) confronted Brazilian society with challenges that were incorporated within the national dialogue and ultimately produced the laws and decrees, as well as the various rules and policy statements, that have guided the evolution of education and health care in the country (Oguisso \& Freitas, 2015; Ventura et al., 2014).

The first formal schools of nursing in Brazil date back to the early 1920s. Initially, the main objective of nursing education was to prepare nurses to care for persons who faced social problems such as urbanization, the care of soldiers who had faced war, and the poor living conditions associated with rapid migration of rural populations into city centres, immigration into the country, and the resultant spread of communicable diseases (Oguisso \& Freitas, 2015). During this developmental period, nursing education was supported by an American nurse, Ethel Parsons, who arrived in Rio de Janeiro in 1922, with a group of about 20 nurses funded by the Rockefeller Foundation to assist with a yellow fever epidemic (Oguisso \& Freitas, 2015). In the course of her work, she met Edith de Magalhães Fraenkel, inviting her to study at the Philadelphia General Hospital School of Nursing. Completing that program in 1925, Miss Fraenkel became Brazil's first graduate nurse (Oguisso, 2007). Parsons and her group, by now calling themselves the Parsons Mission, set up a school for nurses to assist the country to deal with both the current and future epidemics. In 1926, this first official school was renamed the Ana Nery School for Nurses in honour of a Brazilian historical figure who had cared for wounded soldiers in the 1864-1870 war with Paraguay (Oguisso \& Freitas, 2015). Both Parsons and Fraenkel were instrumental in bringing the Nightingale model of nursing education into the Brazilian context, and ultimately establishing a number of nursing schools within hospitals (Oguisso, 2007; Oguisso \& Freitas, 2015; Severo \& Siqueira, 2013).

The Brazilian Nurses Association (ABEN), also formed in 1926, began to play a fundamental role in the coordination of nursing education. To this day, it remains the most important space for lively debate about nursing education and for establishing the guidelines needed to improve it. The numerous political transitions over the twentieth century brought about new ways of thinking about both education and health care, leading to an increase in the number of the undergraduate nursing programs across the country and also the emergence of the country's first master's (1972) and doctoral Programs (1981), which were of critical importance in the development of competencies for nurse educators and improving the quality of higher education in the profession (Oguisso \& Freitas, 2015). Throughout these educational reform processes, Brazilian universities actively sought out novel approaches to support learning and developing capacity in the central tasks of nursing research and service.

Health care reform processes also brought forward an expanded understanding of health, leading Brazilians to appreciate the value of optimally empowering the person with respect to agency in regard to health promotion and maintenance, to bring about a sense of both wellness and quality of life. In this way, the nation's political processes reflected recognition of the complexity of the social realities shaping health care. Recognizing the 
role that their country's distinctive history had played in shaping the opportunities available for developing the profession, nurse educators took up this challenge to deepen their understanding of the social and political problems affecting their nation. As a result, Brazilian nursing educational development has benefitted from deep construction and deconstruction of the social concepts that undergird the profession.

Over time, nursing education leadership has increasingly recognized that complex aspects of Brazilian reality inform the various roles of caregivers, leaders, educators and researchers toward which they are preparing the next generation. In its health reform, known as the Unified Health System (SUS), Brazil is steering its attention from a model characterized by a biomedical acute care focus toward a more integrated model that attends to the continuity between care settings, with an increasing emphasis on primary care and community services. Adopting the ethical-doctrinal principles of universality, equity and integrality of care (Mendes, 2010; Paim, Travassos, Almeida, Bahia, \& Macinko, 2011; Souza \& Costa, 2010), the system's overarching objective is to address the country's vast health inequities by making health a public service, offering primary, secondary and tertiary care services to all citizens. The Brazilian SUS has thus been tasked with undertaking the full spectrum of health promotion, health surveillance, vector control, and health education, all with the aim of ensuring that all members of the population have continuity of care through primary, specialist outpatient, and hospital levels (Paim et al., 2011).

Despite profound advances since the beginning of the 1990s, SUS remains a health system under continual development, struggling to enact its vision of universal and equitable coverage (Paim et al., 2011). Although many improvements have been realized at both primary and acute care levels in recent years, the daily practice of nursing still reveals a hegemonic system, still grounded in the Flexnerian model, in which services prioritize curative, hospital and super-specialized care in areas of economic and corporate interests (Viegas \& Penna, 2013). Thus, in the face of enormous economic, political and social barriers, and despite a national will that has provided clear direction, major obstacles continue to impede the implementation of these universal access principles (Mendes, 2010; Paim et al., 2011; Souza, 2009).

In the context of these broad social and health system level challenges as well as the changes facing the profession in a dynamic and globalized world (Rozendo, Salas, \& Cameron, 2017), the appropriate educational approach for nursing has become a matter of wide debate. The Brazilian Nursing Association and many university partners have been involved in an effort to construct what they envision as a transformative nursing curriculum. Since the endorsement of National Curricular Guidelines in 2001, the central objective of these partners has been to build an academic professional profile of relevant competencies, skills and content, and approaches to training compatible with national and international standards, such that nursing graduates will be capable of effectiveness within the evolving SUS context and in enacting the roles envisioned in the Brazilian Health Reform process (Lucchese, Vera, \& Pereira, 2010; Moraes \& Costa, 2016). This aspirational document defines the principles, foundations, conditions and procedures for general nursing education guided by the humanistic vision of meeting the social demands of the Brazilian population (Fernandes \& Rebouças, 2013; Lucchese et al., 2010; Moraes \& Costa, 2016).

In light of this evolving vision of nursing competencies, nursing education has had to transform from a curricular focus on singular problems, framed by a conventional concept of disease, toward a curricular focus on complex illness contexts and the population level challenge of health promotion. These include an expanding set of relevant considerations such globalization and global disasters, changing demographics, social determinants of health, technological advancements, and the environments within which nurses learn and practice (Veltri \& Barber, 2016, p.73). Traditional disciplinary teaching is being transformed from a fixed model of pedagogy to one that reflects the more Freirian notion of conscientization (Freire, 1972; Halman, Baker, \& Ng, 2017; Michaels \& Reed, 2011). In practice, this means that curriculum and pedagogy are increasingly characterized by constructivist teaching processes, active learning methodologies, creative delivery modalities and optimized formative evaluation systems (Lima, Feuerwerker, Padilha, Gomes, \& Hortale, 2015).

Thus, Brazilian nursing has found its way over a century of development into a well-established educational and professional infrastructure actively taking its place in the wider discussions affecting the health of the Brazilian nation. Trying to provide universal health care with an emphasis on prevention and primary care rather than directing all of its resources to the specialty and acute care sectors remains a highly complex social and political challenge for Brazil. However, nursing education has responded by envisioning approaches to training the next generation of nursing professionals with a clear understanding of global health such that they can move in a dialectical manner between the contextual factors of health (such as aging of the population, epidemiological transition, and scientific and technological advances) and the internal factors of health service delivery (such as organizational culture, resources, incentive systems, organizational structure and leadership style and management) (Mendes, 2010).

The great challenge of this next century of nursing educational development in Brazil will be to prepare professional nurses capable of meeting the demands of complex care related to a society with highly complex and contradictory social realities. They will need the knowledge and abilities to assist informed health care con- 
sumers, understand science, use technology, stem rising costs, provide quality health care and protect the safety of patients, advocate for effective health policy, actively participate in the health care system with competent, empowered human capital. (Veltri \& Barber, 2016, p.82)

Clearly the ideals to which the nursing educational leadership community in Brazil aspires are lofty and visionary. However, their history of working together across nursing professional and educational sectors and engaging the profession actively at a policy level will serve them well in the coming years. And in this wider context, given the enormity of their nation's population health challenge and the fiscal realities of health service delivery, they will continue to be called upon to keep that visionary ideal alive.

\section{Canada: culture and conscience}

Canada's history of two unique and distinct colonizing societies, each with differing values, has dominated and shaped politics and economy throughout the country's history (Lower, 1977). The French settled in 'New France' on the North American continent early 17th century and have continued to uphold the language and a distinctive set of cultural values. Settlers from Great Britain arrived many decades later. The two societies initially cohabited in a fractious manner but ultimately came together as a result of various internal and external forces to establisha confederation in 1867. For much of its history, Canada has celebrated and enshrined in its structures the idea of those two "founding nations," with English evolving to become the dominant influence over a majority of the country's regions and sensibilities, as signified by its founder membership in the Commonwealth of Nations, the 52 sovereign states with British colonial history, in 1931 (Commonwealth Secretariat, n. d). It is only in its more recent years that the country has come to meaningfully attend to the reality that the land it occupies was populated by a wide range of ancestral peoples long before English and French settlers arrived and for whom the emerging Canadian policy framework was intentionally and systematically discriminatory (Allan \& Smylie, 2015; Fridkin, 2012). Since its confederation, the country has continued to expand its ranks through significant waves of immigration, initially primarily from Europe and the Commonwealth countries, and over the last century from an increasingly wide diversity of nations. As "a country of immigrants" (a common expression which naturally excludes the indigenous nations), multiculturalism has come to be a defining core value of the Canadian consciousness (Grifith, 2015; Tierney, 2007), despite the longstanding pattern of disregard of the important cultures of is original peoples.

Canada's early settlers shaped nursing education between 1632 to 1683 beginning with the recruitment of French religious women and trained under the religious nursing orders in French Canada (Baker, Guest, Jorgenson, Crosby, \& Boyd, 2012). Jean Mance, an immigrant from France, established the Hotel Dieu Hospital that became the precursor to the establishment of religious nursing orders (Baker et al., 2012; Pringle, Green, \& Johnson, 2004). These religious nursing orders established an effective nursing education system to train nurses in the hospitals and these nurses then delivered health care services in their own communities. In English Canada, nursing education was secularized by a physician, Dr Theophilus Mack who, with the assistance of two Florence Nightingale-trained nurses, began to provide an alternate model for nursing education in 1874 (Baker et al., 2012; Pringle et al., 2004). Although secularization was initially intended to train nurses outside of the religious context and beyond the direct control of hospitals, due to the need for nursing services provided in hospitals by nursing students, much of the practice of nursing and delivery of nursing education continued to be hospital-based and managed (Baker et al., 2012; Pringle et al., 2004). The tensions between education and service with respect to the appropriate setting for nursing educuation dominated the revisioning of nursing education up to the end of the twentieth century (Baker et al., 2012).

By 1909, 70 Canadian hospital nursing schools had been established. In 1910, in the USA, the Flexner Report on medical education prompted a major initiative to relocate medical education into the universities (Paul \& Ross-Kerr, 2011). In the aftermath of that report, nursing in both Canada and the USA began to consider the development of university-based educational programs. The first university degree granting program among the Commonwealth Nations was established in Canada, at the British Columbia School of Nursing, in 1919 (Zilm \& Warbinek, 1994). In addition to the advent of baccalaureate nursing programs, the Canadian Red Cross Society began to prepare trained nurses for public health work, and those certificate programs were delivered by the universities (Pringle et al., 2004).

The modernization of Canadian nursing education early in the twentieth century was not without its challenges. The university-based nursing education programs reflected a "sandwich" or "non-integrated" model where the first and last years were university-based while the middle years involved hospital training (Baker et al., 2012; Pringle et al., 2004). Learning was not well coordinated and the university had no jurisdiction over the middle years of the program (Dick \& Cragg, 2003). As a result of those disjunctures, in the early 1940s, the universities began to shift their program delivery models to integrate the theoretical and practical components 
of nursing education and provide oversight to clinical learning. Another challenge during this same period was gender bias that took the form of assumptions around the inferiority of women, including a public impression that the work of nurses was merely an extension of their domestic roles and responsibilities. This attitudinal context required nursing educational programs to rely on medical authority for substantive expertise in teaching and for curricular direction (Baumgart \& Kirkwood, 1990).

Nursing education reform was also informed by and inextricably linked to various nursing education reports, the evolution of politics in Canada, and the health of the nation. The creation of the Dominion of Canada with the passing of the British North America Act in 1867 included identified responsibilities of federal and provincial regulation of health care and education, and began the national discussion of nursing education (Baker et al., 2012). In 1927, because of concerns with hospital-based training programs, the national government charged Dr George Weir with surveying 145 nurse training schools across Canada, collecting data from 2200 student nurses and 2300 physicians (Ross-Kerr \& Wood, 2011; Weir, 1932). The Weir Report (1932) contained several key recommendations including increasing admission qualifications into nursing programs, having university training programs award nursing degrees rather than diplomas, and requiring hospitals to have a minimum bed and patient capacity to host a training program, ultimately leading to the closure of many small schools of nursing and improvement in nursing educational programs. Although nursing education remained predominantly hospital-based for another half century, by the 1950s Canada had ten university baccalaureate programs and two university-based diploma programs (Baker et al., 2012). What ultimately separated nursing education from service was Emmett Hall's (1964) Royal Commission on Health Services report. Among many of his recommendations were two key directives: the development of master's level programs in both English and French and bringing an end to service-based education in hospital diploma programs. Although hospital programs persisted into the 1990s (Pringle et al., 2004), Hall's report accelerated the proliferation of baccalaureate programs in universities and sparked the development of new forms of diploma nursing education in community colleges (Baker et al., 2012). For some time, however, diploma educated graduates were preferred by employers due to the familiarity of their service-based training. To counter this, the universities began to introduce clincal preceptorships into their programs to ensure their graduates had equal opportunities to demonstrate their value.

By the 1980s, the Canadian nursing profession had taken up the charge to make the baccalaureate degree the standard "entry-to-practice" (Baker et al., 2012; Pringle et al., 2004). The Canadian Nurses Association (CNA), begun in 1908 as the Canadian National Association of Trained Nurses and renamed in 1924, fully endorsed this transition, propelling the nursing education leadership community into a lenthy period of trying to persuade the provincial governments, which held responsibility for health and education, of the value associated with the increased cost.Various collaborative efforts were initiated to share the educational effort between universities and non-degree granting institutions, and the curricula across the country became more pluralistic and diverse approach in preparing nurses for practice, knowledge development, and understanding of the profession (Baumgart \& Kirkwood, 1990; Bramadat \& Chalmers, 1989). With the increasing need for baccalureate graduates, interest in graduate nursing education grew. Masters programs, which had been few and far between, began to proliferate across the country, and doctoral programs with an emphasis on research followed in the early 1990s. National standards for nursing educational programs and national accreditation soon followed.

Throughout these reconfigurations of the educational model across the provincial jurisdictions over time, a coherent and shared national consciousness about the role and purpose of nursing education in Canada remained quite strong. Educational program leaders shared policy strategizing through a voluntary national organization, formed in 1942 and now known as the Canadian Association of Schools of Nursing (Baker et al., 2012). Based on Hall's national Royal Commission, the ideal of a comprehensive universal health services program for all Canadians was passed in the Medical Care Act of 1966, and further enshrined in Canadian sensibilities with the Canada Health Act of 1984 (Taylor, 1987). The five principles of that Act (public administration, comprehensiveness, universality, portability and accessibility), although intended primarily to guide health insurance financing, have evolved to become deeply embedded and enduring core values about health care across Canadian society (Baer, Grabb, \& Johnston, 1993; Lipset, 2006), and among the most cherished ideals within Canadian nursing (Storch, Starzomski, \& Rodney, 2013). As nursing scholarship has evolved over time, Canadian nurse leaders and researchers have become internationally renouned for their focus on equity-based health service, social determinants of health, cultural safety, intersectionality, and a harm reduction philsophy, all aspects of reaching out to the most marginalized members of society as a hallmark of a nursing angle of vision. These ideas have become deeply entrenched with nursing curricula across the country, and integrated into theory and practice competencies for entry into the profession.

While celebrating and supporting multiculturalism and the distinctive needs and preferences of a diverse population has long been a well recognized component of Canadian nursing education (Griffith, 2015), the profession, like the rest of Canada, has been slow to take up its share of responsibility with respect to Canada's indigenous populations (Bourque Bearskin, 2016). However, the landmark report of the Truth and Reconcilia- 
tion Commission of Canada, which began in 2008 and tabled its final report in 2015, has presented the country with a sharp and definitive call to action (TRC, 2015). Nursing has accelerated its efforts to play its part in healing the deep wounds of racist policies, intergenerational trauma and social discrimination that have so profoundly affected Indigenous communities across Canada (Baker et al., 2012; Canadian Nurses Association, 2014). This dedicated attention to ensuring that every nurse in the country understands the history and assumes personal responsibility for a part in undoing past wrongs will be a part of the fabric of Canadian nursing education well into the next generation. Although this commitment to systems and models of care that are driven by the common social good may not be shared by all nurses in all other national contexts (Lipscomb, 2017), they are likely to remain a deeply ingrained foundation of the Canadian nursing educational ethos.

\section{Reflections}

Through deepening our reflections on how the distinctive features of our countries' histories and national cultures have so profoundly shaped many of the challenges, conditions and values driving the advancement of nursing education in our three different contexts, we have become aware of how much more there is to the texture and nuance of curriculum and pedagogy than just our common nursing epistemological foundations. In order to effectively prepare graduates to take their rightful place within the complexities of our different national sensibilities and structures, and to ensure that they can take the profession forward in a direction that optimizes its contribution to society, it seems essential to ensure vigorous attention to this vitally important but often neglected backdrop in our educational planning. That which is likely self-evident to our leaders rarely filters down to our faculty members or students. And it seems apparent that we have not been a profession that has fully prepared its next generation for the public policy and political advocacy competencies needed to address our national cultural and contextual realities (Staebler et al., 2017).

We believe that strategic learning experiences to enable a critical understanding of their own national history and social nature relative to those in other parts of the world would help neophyte nurses better appreciate the distinctive aspects of the health care systems into which they are entering and be better positioned to play their role in shaping the manner in which their profession develops over the course of their careers. We have found it highly informative to reflect on our own contexts through trying to explain them to others, and engage with the self reflection that another reality can inspire. In becoming accustomed to thinking about nursing education as a unitary whole, we may have forgotten to seek out that which is different.

We therefore challenge the idea of a singular ideal for how nursing and nursing education should operate in the world nor a universal path for developing our distinctive nursing systems. Rather, as with our patients, each nation does seem to have its own way of being; each nursing jurisdiction may be far better served by investing in understanding how best to work within its own context rather that than trying to meet an idealized international standard. The typical developmental strategy of seeking to mimic approaches that have worked in more advanced contexts may be much less helpful to developing nations than will be a more indepth social and political appreciation for their own rich nursing history. By understanding styles and fashions of nursing education as a manifestation of the national cultures from which we have come, we can better educate nurses to understand and serve the world they actually live in.

\section{References}

Allan, B., \& Smylie, J. (2015). First Peoples, second class treatment: The role of racism in the health and well-being of Indigenous Peoples in Canada. Toronto, ON: Wellesley Institute.

Baer, D., Crabb, E., \& Johnston, W. (1993). National character, regional culture, and the values of Canadians and Americans. Canadian Review of Sociology/Revue Canadienne De Sociologie, 30(1), 13-36.

Baker, C., Guest, E., Jorgenson, L., Crosby, K., \& Boyd, J. (2012). Ties that bind: The evolution of education for professional nursing in Canada from the 17th to the twenty-first century. Ottawa: Canadian Association of Schools of Nursing/Association canadienne des écoles de sciences infirmières. Retrieved from https://www.casn.ca/wp-content/uploads/2016/12/History.pdf

Baumgart, A., \& Kirkwood, R. (1990). Social reform versus education reform: University nursing education in Canada, 1919-1960. Journal of Advanced Nursing, 15, 510-516.

Bourque Bearskin, R. L. (2016). Through the lens of truth and reconciliation: Next steps. The Canadian Nurse, 112(2), 36. Retrieved from https://www.canadian-nurse.com/articles/issues/2016/march-2016/through-the-lens-of-truth-and-reconciliation-next-steps

Bramadat, J., \& Chalmers, K. (1989). Nursing education in Canada: Historical 'progress' - contemporary issues. Journal of Advanced Nursing, 14, $719-726$. 
Canadian Nurses Association. (2014). Aboriginal health nursing and aboriginal health: Charting policy direction for nursing in Canada. Ottawa: Author. Retrieved from https://www.cna-aiic.ca/ /media/cna/page-content/pdf-en/aboriginal-health-nursing-and-aboriginalhealth_charting-policy-direction-for-nursing-in-canada.pdf?la=en

Chan, S., \& Wong, F. (1999). Development of basic nursing education in China and Hong Kong. Journal of Advanced Nursing, 29 (6), $1300-1307$.

Chen, K. (1999). Missionaries and the early development of nursing in China. Nursing History Review, 4, 129-149.

Commonwealth Secretariat. (n. d). FAQs. Retrieved from https://web.archive.org/web/20080514162902/ http://www.thecommonwealth.org/FAQs/20706/faqs/

Dick D, D., \& Cragg, B. (2003). Undergraduate education: Development and politics. In M. McIntyre \& E. Thomlinson (Eds.), Realities of Canadian nursing: Professional, practice, and power issues (pp. 182-204). Philadephia, PA: Lippincott Williams \& Wilkins.

Egenes, K. J. (2018). History of nursing. In C. Roux \& J. A. Halstread (Eds.), Issues and trends in nursing: Practice, policy, and leadership (pp. 3-30). Burlingon, MA: Jones \& Bartlett.

Fernandes, J. D., \& Rebouças, L. C. (2013). Uma década de diretrizes curriculares nacionais para a graduação em enfermagem: Avanços e desafios [A decade of national curriculum guidelines for graduation in nursing: Advances and challenges]. Revista Brasileira De Enfermagem, 66, 95. Retrieved from. http://dx.doi.org/10.1590/S0034-71672013000700013

Freire, P. (1972). Pedagogy of the oppressed (30th Anniversaryedn), (M. B. Ramos, Trans.). London: Continuum.

Fridkin, A. (2012). Addressing health inequities through Indigenous involvement in health policy discourses. Canadian Journal of Nursing Research, 44(2), 108-122.

Gao, -L.-L., Chan, S. W.-C., \& Cheng, B.-S. (2012). The past, present and future of nursing education in the People's Republic of China: A discussion paper. Journal of Advanced Nursing, 68(6), 1429-1438.

Griffith, A. (2015). Multiculturalism in Canada: Evidence and anecdote. Ottawa: Anar Press.

Hall, E. (1964). Royal commission on health services. Ottawa, ON: Covernment of Canada.

Halman, M., Baker, L., \& Ng, S. (2017). Using critical consciousness to inform health professional education: A literature review. Perspectives in Medical Education, 6(1), 12-20. doi:10.1007/s40037-016-0324-y

Hesketh, T., \& Xing, Z. W. (2005). The effect of China's one-child family policy after 25 years. New England Journal of Medicine, 353, 1171-1176.

$\mathrm{Li}, \mathrm{X}$. (2014). Innovative new opportunity for the development of nursing in China. International Journal of Nursing Sciences, 1, 131-133.

Lima, V. V., Feuerwerker, L. C. M., Padilha, R. D. Q., Gomes, R., \& Hortale, V. A. (2015). Activators of processes of change: A proposal oriented to the transformation of educational practices and the training of health professionals. Ciência \& Saúde Coletiva, 20(1), 279-288; Retrieved from https://dx.doi.org/10.1590/1413-81232014201.21992013

Lipscomb, M. (2017). Nursing values: Divided we stand. Nursing Inquiry, 24(3), e12209. doi:10.1111/nin.12209

Lipset, S. M. (2006). The Canadian identity. International Journal of Canadian Studies, 33, 83-98.

Lower, A. R. M. (1977). Colony to nation: History of Canada (5th ed.). Toronto: McClelland \& Stewart.

Lu, J., Grypma, S., Cao, Y., Bu, L., Shen, L., \& Davidson, P. M. (2018). Historically-informed nursing: A transnational case study in China. Nursing Inquiry, 25(1), e12205. doi:10.1111/nin.12205

Lucchese, R., Vera, I., \& Pereira, W. R. (2010). The public health policies - SUS - as a reference for the teaching-learning process of nurse. Revista Eletrônica De Enfermagem, 12(3), 562-566. Retrieved from https://www.revistas.ufg.br/fen/article/viewFile/11144/7877

Mendes, E. V. (2010). As redes de atenção à saúde [Health care networks]. Ciência \& Saúde Coletiva, 15(5), 2297-2305. doi:10.1590/S141381232010000500005

Michaels, C., \& Reed, P. G. (2011). Community -based nursing praxis as a catalyst for generating knowledge. In P. G. Reed \& N. B. Crawford Shearer (Eds.), Nursing knoweldge and theory innovation: Advancing the science of practice (pp. 123-132). New York: Springer.

Moraes, B. A., \& Costa, N. M. S. (2016). Understanding the curriculum the light of training guiding health in Brazil. Revista Da Escola De Enfermagem Da USP, 50(spe), 9-16. doi:10.1590/S0080-623420160000300002

Mossialos, E., Djordjevic, A., Osborn, R., \& Sarnak, D. (Eds.). (2017). International profiles of health care systems. New York \& Washington: The Commonwealth Fund. Retrieved from http://www.commonwealthfund.org/ /media/files/publications/fundreport/2017/may/mossialos_intl_profiles_v5.pdf

Oguisso, T. (2007). Trajetória histórica e legal da enfermagem [History and legal trajectory of nursing] (2nd ed.). São Paulo: Manole.

Oguisso, T., \& Freitas, G. F. (2015). Brazilian nursing history on the shoulders of giants. International Nursing Review, 62(1), 75-81. doi:10.1111/inr.12154

Paim, J., Travassos, C., Almeida, C., Bahia, L., \& Macinko, J. (2011). The Brazilian health system: History, advances, and challenges. Lancet, 377(9779), 1778-1797. doi:10.1016/S0140-6736(11)60054-8

Paul, P., \& Ross-Kerr, ]. (2011). The origins and development of nursing education in Canada. In ]. Ross-Kerr \& M. Wood (Eds.), Canadian nursing: Issue \& perspectives (5th ed., pp. 327-358). Toronto, ON: Elsevier Canada.

Pringle, D., Green, L., \& Johnson, S. (2004). Nursing education in Canada: Historical review and current capacity. Ottawa: The Nursing Settor Study Corporation, Government of Canada. Retrieved from https://www.nurseone.ca/ /media/nurseone/page-content/pdfen/nursing_education_canada_e.pdf?la=en

Ross-Kerr, J., \& Wood, M. (2011). Canadian nursing: Issues and perspectives. Toronto, ON: Elsevier Canada.

Rozendo, C. A., Salas, A. S., \& Cameron, B. (2017). Problematizing in nursing education: Freire's contribution to transformative practice. Nurse Education Today, 51, 120-123. Retrieved from https://doi.org/10.1016/j.nedt.2016.08.009

Severo, D. F., \& Siqueira, H. C. H. (2013). Interconnection between the History of Brazilian Nursing Education and the Ecosystem Thoughts. Revista Brasileira De Enfermagem, 66(2), 278-281. Retrieved from https://dx.doi.org/10.1590/So034-71672013000200019

Souza, G. C. A., \& Costa, I. C. C. (2010). Twenty years of SUS: Reflections in a context of changes. Saúde E Sociedade, 19(3), 509-517. doi:10.1590/S0104-12902010000300004

Souza, L. E. P. F. (2009). The needed Brazilian health system and the possible Brazilian health system: Management strategies. An experience-based reflection. Ciência \& Saúde Coletiva, 14(3), 911-918. doi:10.1590/S1413-81232009000300027 
Staebler, S., Campbell, J., Cornelius, P., Fallin-Bennett, A., Fry-Bowers, E., Kung, Y. M., ... Miller, J. (2017). Political and policy advocacy: Comparison study of nursing faculty to determine current practices, perceptions, and barriers to teaching health policy. Journal of Professional Nursing, 33(5), 350-355. doi:10.1016/j.profnurs.2017.04.001

Storch, J. L., Starzomski, R., \& Rodney, P. (Eds.). (2013). Toward a moral horizon: Nursing ethics for leadership and practice (2nd ed.). Toronto: Pearson.

Taylor, M. G. (1987). The seven decisions that created the Canadian health insurance system and their outcomes (2nd ed.). Montreal \& Kingston: McGill-Queen's University Press.

Tierney, S. (Ed.). (2007). Multiculturalismand the Canadian constitution. Vancouver \& Toronto: UBC Press.

Truth and Reconciliation Commission of Canada. (2015). Honoring the truth, reconciling for the future: Summary of the final report of the Truth and Reconciliation Commission of Canada. Ottawa: Author. Retrieved from http://www.myrobust.com/websites/trcinstitution/File/Reports/Executive_Summary_English_Web.pdf

Veltri, L. M., \& Barber, H. (2016). Forces and issues influencing curriculum development. In D. M. Billings \& ]. A. Halsead (Eds.), Teaching in nursing: A guide for faculty (5th ed., pp. 73-88). St Louis: Elsevier.

Ventura, C. A. A., Mendes, I. A. C., Wilson, L. L., Godoy, S. D., Tamí-Maury, I., Zárate-Grajales, R., \& Salas-Segura, S. (2014). Global Health Competencies according to Nursing Faculty from Brazilian Higher Education Institutions. Revista Latino-Americana De Enfermagem, 22(2), $179-186$. doi:10.1590/0104-1169.2996.2400

Viegas, S. M. F., \& Penna, C. M. M. (2013). The construction of integrality in the daily work of health family team. Escola Anna Nery Journal, 17(1), 133-141. Retrieved from http://www.scielo.br/scielo.php?script=sci_arttext\&pid=S1414-81452013000100019

Wang, C. C., Whitehead, L., \& Bayes, S. (2016). Nursing education in China: Meeting the global demand for quality healthcare. International Journal of Nursing Sciences, 3(1), 131-136.

Watt, J. (2004). Breaking into public service: The development of nursing in modern China, 1870-1949. Nursing History Review, $12,67-96$.

Weir, G. (1932). Survey of nursing education in Canada. Toronto, ON: The University of Toronto Press.

$\mathrm{Xu}, \mathrm{Y}$, Xu, Z., \& Zhang, J. (2000). The nursing education system in the people's republic of China: Evolution, structure and reform. International Nursing Review, 47(4), 207-217.

Yan, Z., An Li, J., \& McDonald, T. (2014). Nursing education development in China (1887-1949): Influences on contemporary nursing. International Nursing Review, 61, 380-388.

Yuhong, J. (2017). Shaping modern nursing development in China. International Journal of Nursing Sciences, 4(1), 19-23.

Zilm, G., \& Warbinek, E. (1994). Legacy: History of nursing education at the University of British Columbia 1919-1994. Vancouver: UBC Press. 